\title{
Chest wall resection and reconstruction for lung cancer: surgical techniques and example of integrated multimodality approach
}

\author{
Mauro Loi ${ }^{1,2}$, Antonio Mazzella ${ }^{1}$, Isacco Desideri ${ }^{3}$, Ludovic Fournel ${ }^{1}$, Emelyne Canny Hamelin ${ }^{1}$, \\ Philippe Icard ${ }^{1}$, Antonio Bobbio ${ }^{1}$, Marco Alifano ${ }^{1}$ \\ ${ }^{1}$ Department of Thoracic Surgery, Paris-Center University Hospital, AP-HP, Paris Descartes University, Paris, France; ${ }^{2}$ Department of Radiotherapy, \\ Hospital Tenon, Paris, France; ${ }^{3}$ Department of Radiotherapy, Università di Firenze, Firenze, Italy \\ Correspondence to: Prof. Marco Alifano. Service de Chirurgie Thoracique, Hôpitaux Universitaires Paris Centre, 27 rue du Faubourg Saint Jacques \\ 75014, Paris, France. Email: marco.alifano@aphp.fr.
}

Submitted Jun 01, 2019. Accepted for publication Jul 18, 2019.

doi: $10.21037 /$ jtd.2019.07.81

View this article at: http://dx.doi.org/10.21037/jtd.2019.07.81

\section{Introduction}

Surgery is a mainstay in the treatment of non-small cell lung cancer (NSCLC). Involvement of chest wall accounts for approximately $5-10 \%$ of operable NSCLC and in such cases extended resection is needed to maximize chances of durable disease control (1). After surgical removal of involved structures, reconstructive procedures are often necessary to maintain or re-establish thoracic cage stability and function, in order to preserve satisfying longterm functional outcome and cosmesis, while dealing satisfactorily with postoperative outcome (2).

Despite advances in surgical procedures and postoperative care and wide availability of prosthetic replacement materials, chest wall surgery stands as a challenge to thoracic surgeon, resulting in a stringent tradeoff between achievement of adequate resection margins and risk of long-term sequelae. Careful candidate selection and surgical planning on individual basis are mandatory. Most notably, chest-invading NSCLC display heterogeneous presentation ranging from parietal pleura infiltration to full-thickness invasion of the chest wall, with or without involvement of neighboring anatomic structures such as intercostal space including neurovascular bundle, vertebrae, mediastinal vascular structure, as well as extra-thoracic soft tissues. Furthermore, chest wall invasion may be posterior, lateral, or anterior: hence, choice of surgical technique is critical. Although no real consensus on appropriate management has been reached yet, it should be pointed out that this is more probably related to the multifaceted presentation of the disease than to real discrepancies on surgical opinions and practices. Moreover, increasing use of multimodal integrated treatment, including chemo- and radiotherapy regimen, as well as induction immunotherapy, is expected to increase the number of currently disqualified patients at presentation who can be considered eligible for curative-intent surgery after preoperative treatments. In our paper we will review major operative modalities in this setting.

\section{Surgical technique}

\section{Incision and demolition}

\section{Posterior approach}

The choice of the surgical incision is established on the results of preoperative imaging assessment with a clever identification of the anatomical structures to be demolished.

Posterolateral thoracotomy is the incision of choice for posterior and lateral aspect of the thoracic wall, allowing resection of all ribs from first to lowest and providing optimum access for every kind of lobar, supra-lobar and infra-lobar lung resection, including bronchial and broncho-vascular sleeve and full nodal dissection. Access to thoracic cavity is generally performed through the $5^{\text {th }}$ intercostal spaces, although for slightly higher or lower located involvement of chest wall, more cranial or caudal intrathoracic access may be performed.

After entering the pleural space, pleural carcinosis is ruled out and assessment of resectability at hilar level is performed, together with evaluation of chest wall involvement: number of ribs in contact with tumors and 


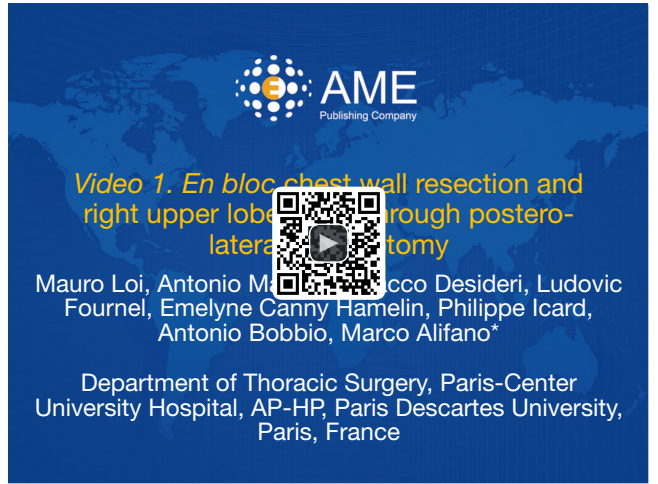

Figure $1 \mathrm{En}$ bloc chest wall resection and right upper lobectomy through postero-lateral thoracotomy (3).

Available online: http://www.asvide.com/watch/33051

possibly necessitating removal, involvement of the first rib, proximity with transverse processes, need to perform posterior partial or total disarticulation of involved rib(s) from vertebrae. The degree of chest wall infiltration may range from parietal pleura to extra-thoracic soft tissues; CT scan and MRI may show signs of infiltration beyond parietal pleura, especially if bone lysis is evident, but, and in most cases, imaging studies show only contact of tumor with chest wall and depth of invasion can be assessed only at surgical (and pathological) examination. Because intraoperative assessment is reliable in evaluating if infiltration is limited at parietal pleura (allowing avoidance of rib resection, with similar oncologic results), extra-pleural resection is generally attempted in doubtful cases (Figure 1): if the plane of dissection is easy and macroscopically satisfactory, full thickness resection is generally not indicated and enbloc pleural and anatomical resection (lobectomy whenever possible) is performed; otherwise if the plane of extrapleural dissection seems not satisfactory, extra-pleural dissection is rapidly abandoned and the operation will proceed to an en bloc chest wall and lung resection (Figure 1). Anyway, en bloc resection may be impossible (bulk mass) or contraindicated (doubtful resectability at hilar level) and discontinuous resection may be allowed (Figure 2).

Incision for a standard postero-lateral thoracotomy allows en-bloc resection of almost all posteriorly and laterally located tumors; when chest wall infiltration involves apical portion of the thorax, the incision can be easily prolonged in the bisector of the scapula-vertebral angle giving access to the first and second ribs as well as to the corresponding vertebra in case of superiorly located tumors, including sulcus tumors with posterior thoracic involvement.
In such cases, the rhomboid muscle is sectioned until the level of the spine of the scapula which is elevated giving access to the insertions of posterior and middle scalene muscles on the second and third ribs (Figure 1). The anterior surgical boundaries of resection through this incision should be considered the clavicular tubercle of the first rib and the costo-chondral articulation for the underlying ribs. If involvement of these structures is present a mixed or exclusively anterior approach should be considered.

Through a posterolateral incision the ribs can be easily freed in their posterior aspect until their articulation with the transversal apophysis of the vertebra. In case of posterior tumor invasion over this landmark the posterior segment including the neck and the head of the rib can be completely removed by rib disarticulation (Figure 2). In such case the paraspinous muscles are elevated and the costo-trasveral joint is exposed. The articular capsule is incised ant the rib disarticulated from the transversal apophysis of the vertebra with a Cobb elevator. Much farer the head of the rib must be bluntly disarticulated from the vertebral body. This maneuver is performed by gentle pushing anteriorly the posterior costal segment playing attention to prevent the fracture of the rib neck. During disarticulation the intervertebral foramen became apparent and care must be taken to not open the dural sac during the transection of the intercostal nervous bundle. Neurovascular bundles must be dissected and ligated to assure hemostasis and prevent liquor leakage from possibly injured diverticula of the dural sac.

In cases of tumor invasion of the posterior arch of the rib with contact of transverse process (even if minimally infiltrated), resection of the transverse process is carried out; in case of larger infiltration of transverse process, intervertebral foramen (or foramina), vertebral lamina, or vertebral body or disk at maximum $1 \mathrm{~cm}$ within the vertebral midline, an hemi-vertebrectomy must be planned (Figure 3). In case of more extensive involvement of vertebral body, a total vertebrectomy is performed. Both hemi-vertebrectomy and total vertebrectomy could be performed in more than one spinal level; three must be considered the maximum number of vertebral body that could be resected.

\section{Anterior/lateral approach}

When the tumor infiltrates the anterior cartilaginous part of the rib or the sternum a lateral or an anterior approach to the thoracic wall should be planned. Lateral or axillary thoracotomy is useful to control the anterior segment of the 

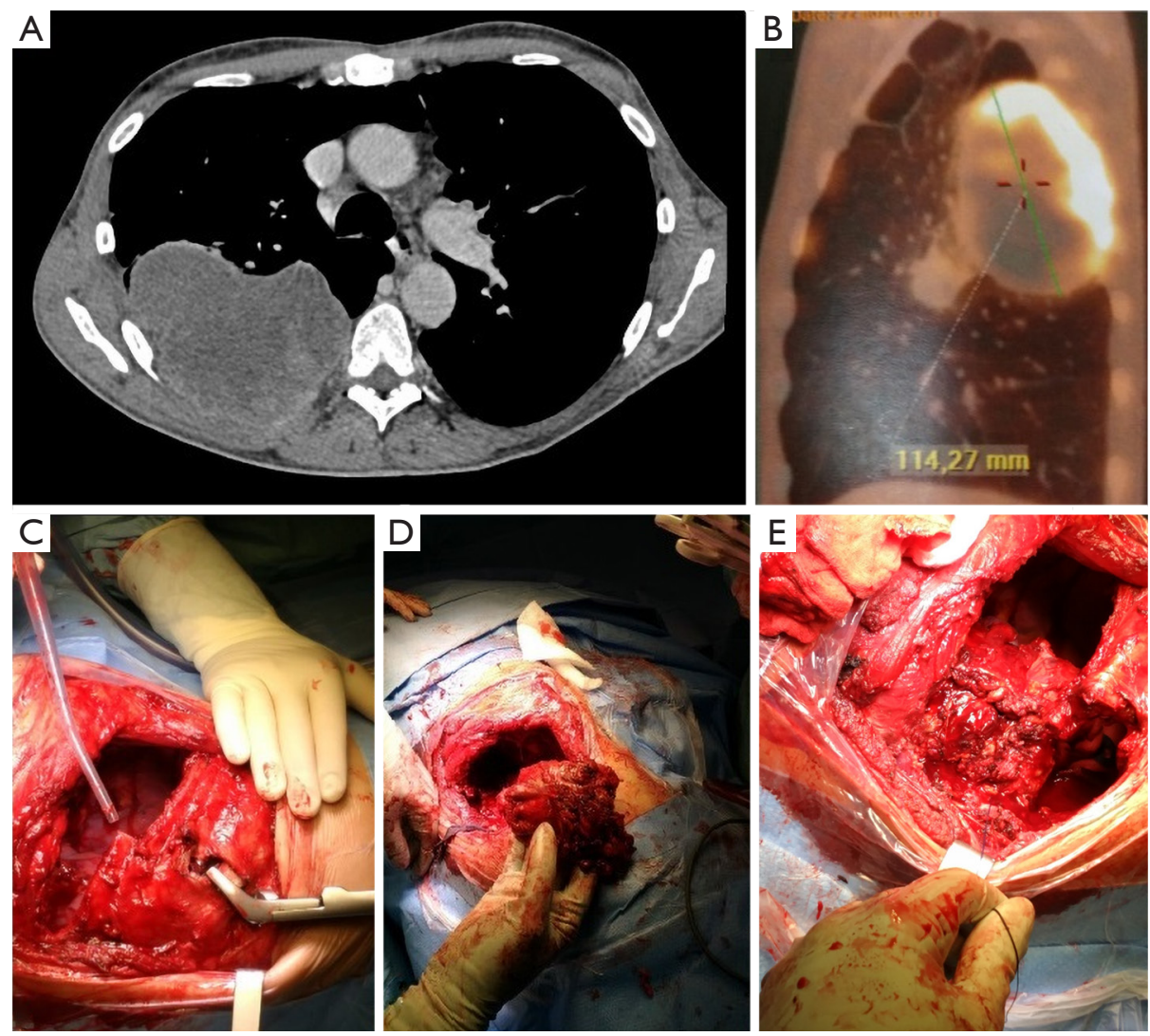

Figure 2 Bulk mass (NSCLC) involving upper and lower right lobes and ribs 4-6 (A,B). Because of bulk mass and doubtful resectability, discontinuous resection was decided. Pneumonectomy has been performed and chest wall resection is carried out by anterior section of ribs 4 to $6(\mathrm{C})$ and posterior disarticulation (from both transverse processes and vertebral bodies) of corresponding ribs. This requires proximal ligatures of intercostal pedicles to assure hemostasis and avoid cerebrospinal fluid leak (D). The specimen is extracted (E). Source: Prof. Marco Alifano. NSCLC, non-small cell lung cancer.
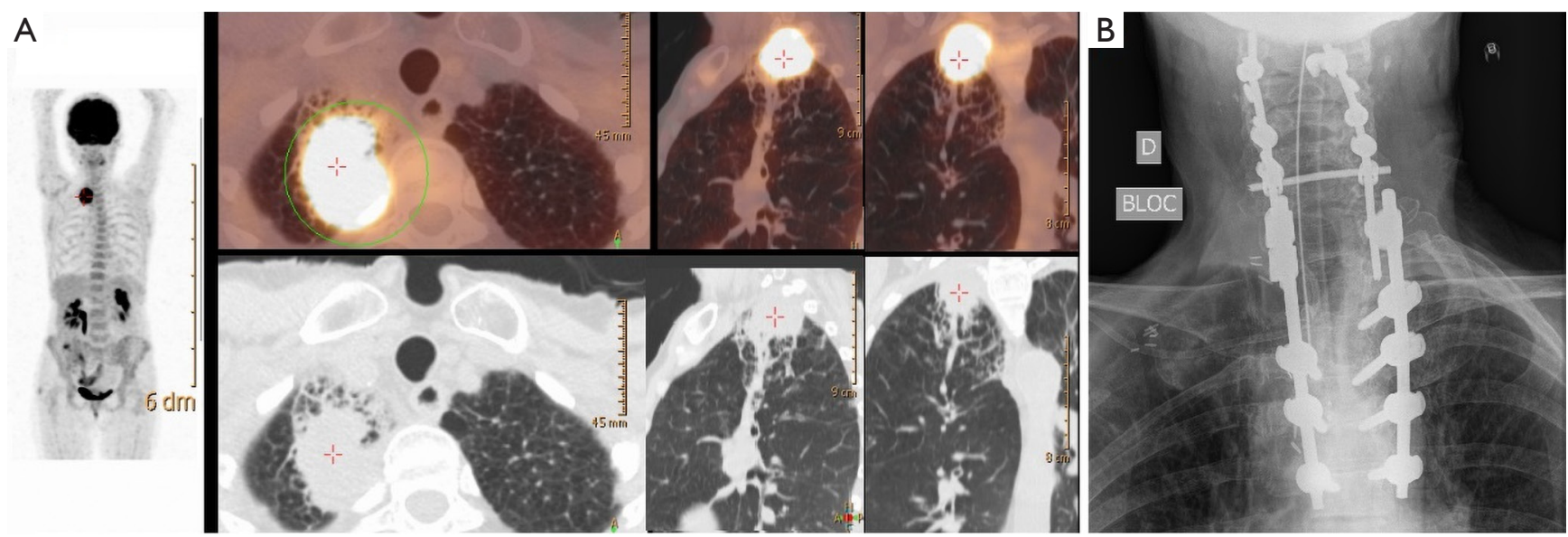

Figure 3 NSCLC involving right upper, ribs 1-2, transverse processes and intervertebral foramen (D1-D2) (A). Resection required en bloc upper lobectomy with chest wall and hemivertebrectomy and stabilization. Postoperative chest X-ray (B). Source: Prof. Marco Alifano. NSCLC, non-small cell lung cancer. 

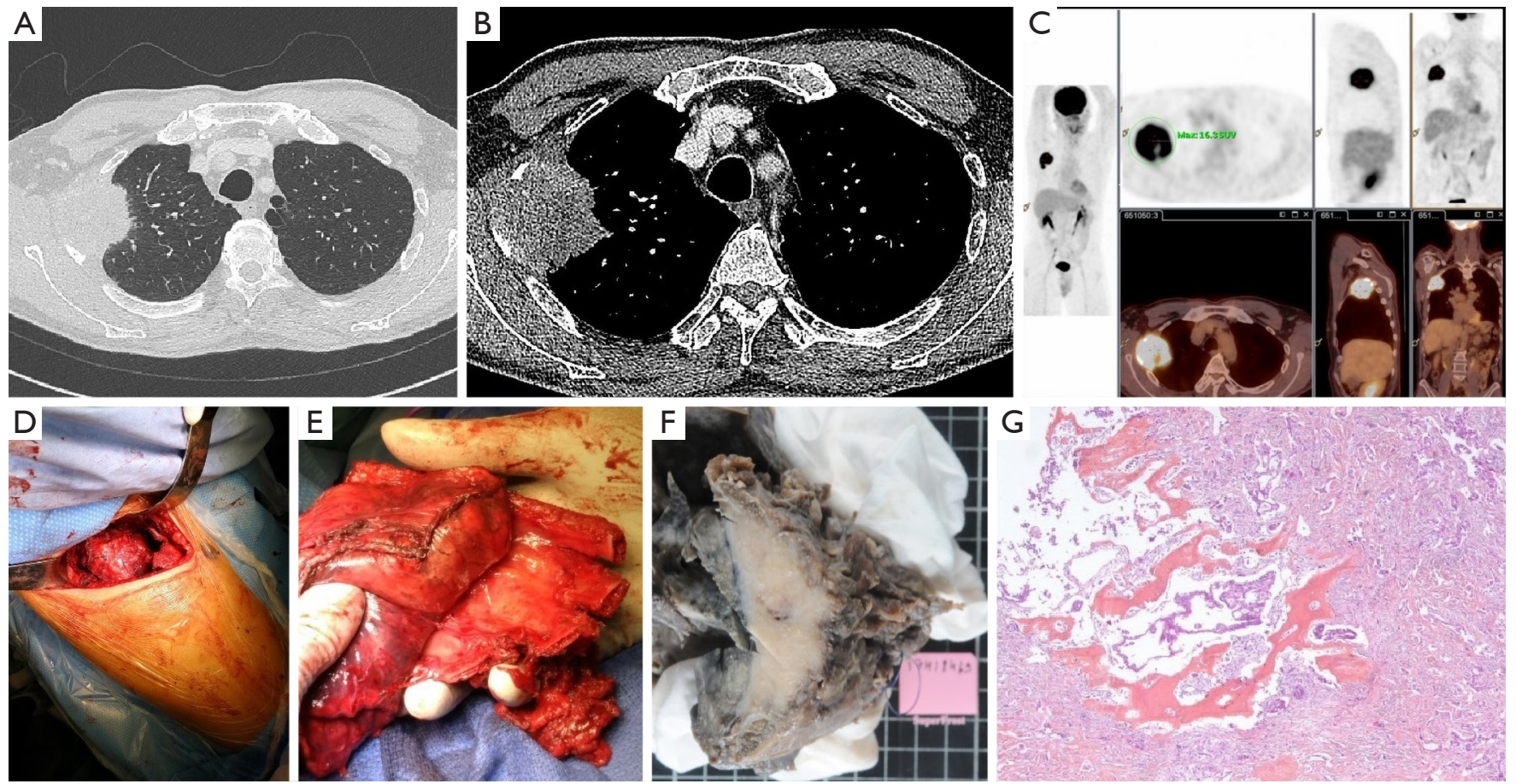

Figure 4 Surgical management of lung cancer involving the later aspect of the chest wall. (A,B,C) Bulk mass (NSCLC) involving right upper lobe and lateral aspect ribs 2-3; (D) en bloc chest wall and lung resection was performed by a lateral approach; (E) view of the operative specimen (chest wall and lung parenchyma) before completion lobectomy in the same operative time; (F) view of the specimen after formalin fixation; (G) pathologic slides (hematoxylin and eosin; original magnification $\times 40$ ) showing bone tissue infiltration. Source: Prof. Marco Alifano. NSCLC, non-small cell lung cancer.

rib and is preferentially employed for tumor infiltrating the lower part of the anterior cage from the third to the fifth rib (Figure 4). On the other hand in those cases in whom the first two ribs are involved as well as in those cases in whom a concomitant mediastinal vascular control should be obtained, an anterior approach is to be planned and it must anticipated whether to perform the lung resection trough the same anterior approach or if a separate posterior incision should be planned.

The most common anterior approach for the first and second rib is trans-manubrial trough a vertical presternocleidomastoid incision which is prolonged over the upper the sternal manubrium and then horizontally two transverse fingers below the clavicle up to the deltopectoral groove. By trans-manubrial approach anterior rib involvement should be limited to the first or the first two ones; otherwise, alternative anterior approaches (e.g., the hemi-clamshell incision) are generally adopted. However, these surgical approaches are not detailed herein, because of a specifically dedicated article in the same issue of the

\section{Fournal of Thoracic Disease.}

Direct sternal involvement by primary lung tumor is exceptional; isolated sternal metastasis of lung cancer is uncommon; this is generally treated by systemic chemotherapy of immunotherapy or targeted treatments and by local ablative treatments. Surgical resection may be exceptionally indicated, and can be performed as a salvage treatment after failures of the standard armamentarium (Figure 5).

\section{Reconstruction techniques}

The chest wall has different proprieties: a part protection of the lung and the hearth from external trauma, however its rigidity (but also compliance) is necessary to generate and maintain a pleural negative pressure ensuring the lung expansion and ventilation secondary to the contraction of the diaphragm and intercostal muscles. The major concern related to the resection of thoracic wall is to avoid a paradoxical lung ventilation because of a flail chest. 
Ultimately esthetic concerns should be considered. Thus, the following principles of reconstruction of the thoracic wall should be taken into account:

* Protect lung and mediastinum;

* Prevent flail chest;

* Use prosthesis only when needed;

- No need for posterosuperior resections;

* Use absorbable prosthesis when possible (Figure 6);

* Non absorbable prosthesis for anterior defects to prevent paradoxical respiration (Figure 5);

* Avoid non-absorbable prosthesis in case of ulcerated/ infected tumors;

* Always cover prosthesis with viable tissue (Figures 6,7);

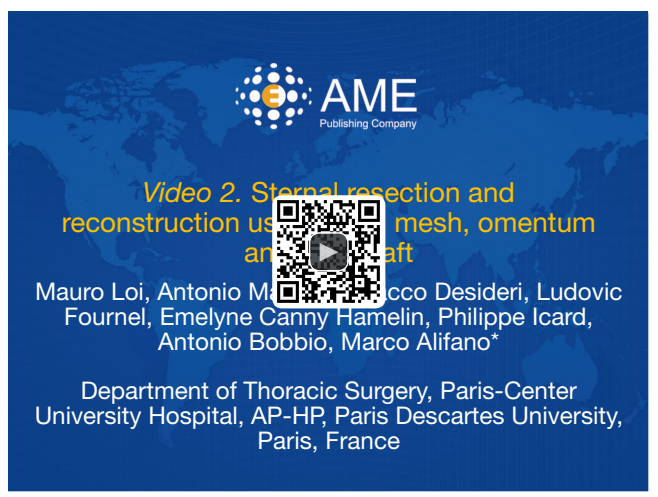

Figure 5 Sternal resection and reconstruction using vicryl mesh, omentum and skin graft (4).

Available online: http://www.asvide.com/watch/33052
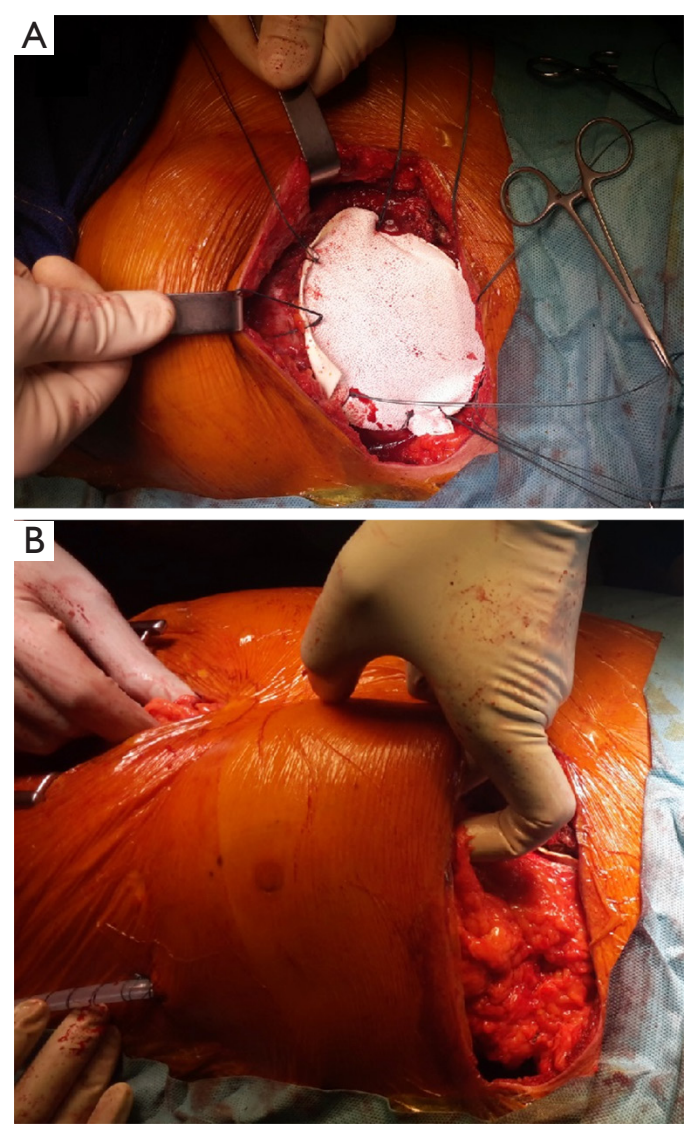

Figure 7 En bloc lung and anterior full-thickness chest wall resection (ribs 2-3) by an anterior approach. Reconstruction is achieved by a Gore-Tex prosthesis (A) covered by a pedicled omentum flap (B). Source: Prof. Marco Alifano.
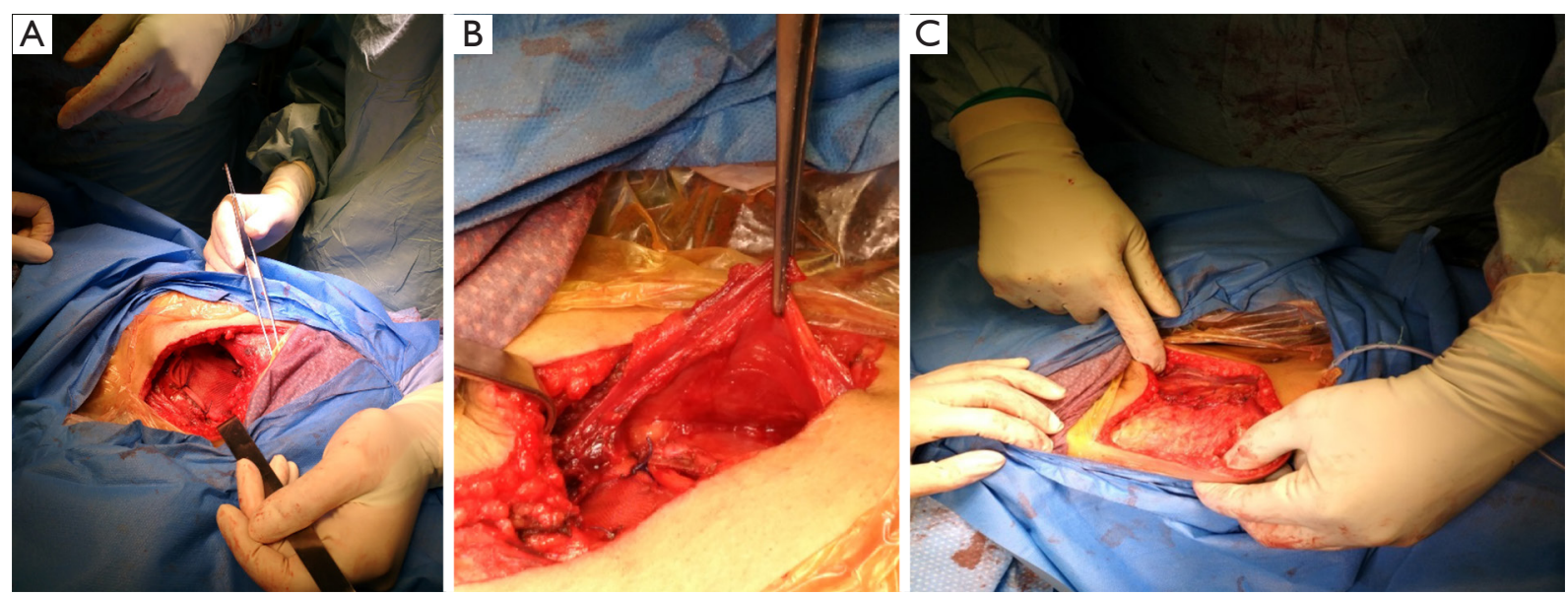

Figure 6 Non-small cell lung cancer (NSCLC) invading chest wall; resection has been performed by a lateral approach (same case as in Figure 3). Reconstruction is achieved by a Vicryl Mesh (A) and pectoralis major and latissimus dorsi unpedicled flaps (B). Operative view before skin closure (C). Source: Prof. Marco Alifano. NSCLC, non-small cell lung cancer. 
- Privilege muscle flap:

- Latissimus dorsi (Figure 6);

- Serratus anterior;

- Pectoralis major (Figure 6);

- Rectus abdominis.

- Omentum is an option if muscles are not available, and more than a simple option in case of concurrent infection (Figure 5);

* Skin coverage may be a concern (wide resection, prior radiotherapy, burns);

- Skin graft on viable and clean tissue and best on omentum (Figure 5);

- Consider myocutaneous flap;

- Availability of a plastic surgeon may be necessary for complex resection.

\section{Discussion}

As a general rule, depth of chest wall invasion is considered as a major prognostic factor that may influence the choice of surgical technique (5-12), in particular if tumor invasion does not extend beyond parietal pleura (13). Preoperative work-up is crucial in determining the surgical technique. At present, computed tomography is frequently used to assess chest wall invasion despite poor accuracy (14); alternative imaging modalities to discern thoracic involvement include surgeon performed ultra-sound (14) or magnetic resonance imaging (15), in particular weighted sequences (disruption of the extra-pleural fat tissue) or cine MR techniques (fixation of the tumor during respiratory motion) (16). Nevertheless, in absence of clearly defined bone or soft tissue invasion at imaging, chest invasion evaluation relies mainly on intra-operative assessment of tumor adhesion to parietal pleura. However, intraoperative assessment sometimes does not allow to precisely indicate the optimal operative procedure. In relation with their experience, some authors conclude that patients with tumor invasion limited to parietal pleura experience improved survival—advocating for exclusive pleurectomy-if extra-pleural dissection can be obtained $(5,17)$. The presence of the parietal pleura may act as a barrier to tumor infiltration, thus use of extra-pleural dissection can limit the extent of the resection without jeopardizing the oncological safety of the procedure (18); however the depth of tumor infiltration and the presence of a cleavage plan with the chest wall is frequently judged on an operator-dependent basis and intraoperative pathologic assessment is rarely contributing: hence, extra-pleural dissection might result in potentially higher number of incomplete resections (17). In patients with tumor infiltration within parietal pleura, Albertucci et al. (12) reported superior survival after full-thickness chest wall resection compared to extra-pleural dissection. According to other reports, including ours $(11,13,17,19)$, patients with invasion within the parietal pleura treated by full-thickness chest wall resection or extra-pleural dissection experienced similar survival rates; most interestingly, in patients who achieved complete resection, local recurrence rates did not differ significantly between the two procedures. It could be therefore speculated that extra-pleural dissection can be safely performed in selected patients with invasion limited to parietal pleura if satisfactory dissection of pleura from the underlying osteo-muscular plane can be achieved.

Of note, full-thickness chest wall resection might be associated to higher mortality risk as compared with extrapleural dissection $(13,16)$, although, according to other reports, chest wall resection may not be burdened by additional morbidity and mortality $(12,17)$.

In case of proven extension beyond parietal pleura, chest wall resection is required. In this setting, en bloc pulmonary and chest wall resection $(7,9-11,20)$ is considered the main surgical option in order to limit intra-pleural tumor dissemination (11). However, discontinuous resection may result in non-inferior outcome (6). According to our practice, discontinuous resection may be proposed in case of doubt about resectability (i.e., posteriorly-located tumors, or N2 nodal stage or extensive hilar involvement) or following an extra-pleural dissection if resection is potentially incomplete.

In case of vertebral involvement, the benefit of surgical treatment is debated, due to technical complexity of the procedure and dismal prognosis of such tumors following resection $(21,22)$. Though long-term follow-up data are scarce, current literature reports encouraging results, in particular after introduction of neoadjuvant treatment regimens (23-30), suggesting 5-year survival ranging from $22 \%$ to $66 \%(23,25,31,32)$. Extreme variability among these figures indirectly may result from heterogeneity in criteria of operability among different Institutions: this finding stresses the importance of careful patient selection in this setting. Procedures involving the thoracic spine, usually coupled with extensive en bloc resection of the posterior chest wall, are burdened by significant perioperative morbidity: early morbidity rates ranging $28-56 \%$, resulting in a mortality rate around 6\% (33-36). In particular, treatment-related neurologic impairment is reported in up to $25 \%$ of cases in the early postoperative period $(33,34,36)$. 
In our recent experience (37) on en-bloc resection of thoracic tumors invading the spine, we reviewed data of 31 patients operated in an 8-year periods for tumors involving the thoracic spine either primarily or after an induction-therapy (20 cases). There were $61.3 \%$ primary lung carcinomas, $12.9 \%$ extra-pulmonary primaries, $9.7 \%$ metastases and $16.1 \%$ benign tumors. Spinal resection (mostly including $\geq 2$ vertebral levels) was combined with lobectomy in almost half cases. There was no in-hospital death, but a major complications rate of $32.3 \%$ including 5 cases of early neurological complications. With a mean followup of 32.1 months, we found a 5 -year overall survival rate of $81.3 \%$ in the whole cohort and $75.0 \%$ in patients with malignancies; 5-year disease-free survival rate was 37.0\% in malignant diseases. Delayed complications occurred in $35.5 \%$ of patients including persistent neurologic deficit $(12.9 \%)$, instrumentation migration $(19.4 \%)$, and local infection (12.9\%). These data allowed us to conclude that en-bloc resection of spinal thoracic tumors offers long-term survival and few recurrences in highly selected patients but is associated with significant delayed mechanical and/or infectious complications.

Generally, the benefit of multimodality management encompassing chemotherapy and radiotherapy strategies in lung cancer invading chest wall is debated. With the exception of superior sulcus tumors, for whom neo-adjuvant chemoradiotherapy is a standard of care (38), current guidelines endorse surgery as the primary treatment modality in T3-4 N0-1 NSCLC patients and limit the use of radiotherapy to the case of incomplete resection; of note, use of postoperative radiation seems beneficial in our experience [ 4 incompletely resected patients treated by postoperative radiotherapy still alive with no evidence of recurrence at $16,45,55$, and 116 months of follow-up (13)] and as reported by other authors (15). Focusing on preoperative treatment, it is unclear whether the use of preoperative chemo-radiotherapy may improve survival compared to chemotherapy (39). However modern series suggest that rates of complete resection may be improved in selected patients following chemo-radiotherapy $(40,41)$. Most interestingly, indirect evidences suggest a possible increased benefit in survival for preoperative radiotherapy in patients with T3N2 NSCLC (42). This is an important issue: since nodal staging is a main determinant of prognosis $(7,11,12,17)$, some authors discourage surgical resection if $\mathrm{N} 2$ disease is recognized $(9,10)$, while others experience $(7,13,17,43)$ consider that mediastinal nodal involvement should not be considered a contraindication to surgery on the basis of encouraging $15-21 \%$ survival at five years in operated patients. While a recent metaanalysis found no benefit of chemo-radiation compared to induction chemotherapy in operable stage IIIA patients (44), it could be speculated that use of chemo-radiation, combined with extended resection, may be of interest in the subset of patients with T3-4 N2 disease in order to increase the rate of complete resections.

Respiratory complications are an important source of morbidity after chest wall resection, in particular in elderly patients (45) or in case of combined pneumonectomy (46). Thus, careful patient selection and availability of specialized facilities for postoperative care are mandatory to limit postoperative deaths.

In conclusion lung cancer invading chest wall remains a challenge for medical and surgical teams; multidisciplinary approach is the key to offer to patients the best available solutions in the optimal timing.

\section{Acknowledgments}

None.

\section{Footnote}

Conflicts of Interest: The authors have no conflicts of interest to declare.

Ethical Statement: The authors are accountable for all aspects of the work in ensuring that questions related to the accuracy or integrity of any part of the work are appropriately investigated and resolved. Informed consent was obtained from the patient for publication of this manuscript and any accompanying images.

\section{References}

1. Stoelben E, Ludwig C. Chest wall resection for lung cancer: indications and techniques. Eur J Cardiothorac Surg 2009;35:450-6.

2. Gaucher $\mathrm{S}$, Lococo F, Guinet $\mathrm{C}$, et al. Indications and Results of Reconstructive Techniques with Flaps Transposition in Patients Requiring Complex Thoracic Surgery: A 12-Year Experience. Lung. 2016;194:855-63.

3. Loi M, Mazzella A, Desideri I, et al. En bloc chest wall resection and right upper lobectomy through posterolateral thoracotomy. Asvide 2020;7:005. Available online: http://www.asvide.com/watch/33051

4. Loi M, Mazzella A, Desideri I, et al. Sternal resection and 
reconstruction using vicryl mesh, omentum and skin graft. Asvide 2020;7:006. Available online: http://www.asvide. $\mathrm{com} /$ watch/33052

5. McCaughan BC, Martini N, Bains MS, et al. Chest wall invasion in carcinoma of the lung. Therapeutic and prognostic implications. J Thorac Cardiovasc Surg 1985;89:836-41.

6. Piehler JM, Pairolero PC, Weiland LH, et al. Bronchogenic carcinoma with chest wall invasion: factors affecting survival following en bloc resection. Ann Thorac Surg 1982;34:684-91.

7. Ricci C, Rendina EA, Venuta F. En bloc resection for T3 bronchogenic carcinoma with chest wall invasion. Eur J Cardiothorac Surg 1987;1:23-8.

8. Watanabe Y, Shimizu J, Oda M, et al. Results of surgical treatment in patients with stage IIIA non-small-cell lung cancer. Thorac Cardiovasc Surg 1991;39:44-9.

9. Allen MS, Mathisen DJ, Grillo HC, et al. Bronchogenic carcinoma with chest wall invasion. Ann Thorac Surg 1991;51:948-51.

10. Shah SS, Goldstraw P. Combined pulmonary and thoracic wall resection for stage III lung cancer. Thorax 1995;50:782-4.

11. Pitz CC, Brutel de la Riviere A, Elbers HRJ, et al. Surgical treatment of 125 patients with non-small cell lung cancer and chest wall involvement. Thorax 1996;51:846-50.

12. Albertucci M, DeMeester TR, Rothberg M, et al. Surgery and the management of peripheral lung tumors adherent to the parietal pleura. J Thorac Cardiovasc Surg 1992;103:8-12

13. Magdeleinat P, Alifano M, Benbrahem C, et al. Surgical treatment of lung cancer invading the chest wall: results and prognostic factors. Ann Thorac Surg 2001;71:1094-9.

14. Tahiri M, Khereba M, Thiffault V, et al. Preoperative assessment of chest wall invasion in non-small cell lung cancer using surgeon-performed ultrasound. Ann Thorac Surg 2014;98:984-9.

15. Padovani B, Mouroux J, Seksik L, et al. Chest wall invasion by bronchogenic carcinoma: evaluation with MR imaging. Radiology 1993;187:33-8

16. Akata S, Kajiwara N, Park J, et al. Evaluation of chest wall invasion by lung cancer using respiratory dynamic MRI. J Med Imaging Radiat Oncol 2008;52:36-9.

17. Downey RJ, Martini N, Rusch VW, et al. Extent of chest wall invasion and survival in patients with lung cancer. Ann Thorac Surg 1999;68:188-93.

18. Burnard RJ, Martini N, Beattie EJ Jr. The value of resection in tumors involving the chest wall. J Thorac
Cardiovasc Surg 1974;68:530-5.

19. Casillas M, Paris F, Tarrazona V, et al. Surgical treatment of lung carcinoma involving the chest wall. Eur J Cardiothorac Surg 1989;3:425-9.

20. Patterson GA, Ilves R, Ginsberg RJ, et al. The value of adjuvant radiotherapy in pulmonary and chest wall resection for bronchogenic carcinoma. Ann Thorac Surg 1982;34:692-7.

21. Dartevelle PG, Chapelier AR, Macchiarini P, et al. Anterior transcervical-thoracic approach for radical resection of lung tumors invading the thoracic inlet. J Thorac Cardiovasc Surg 1993;105:1025-34.

22. Maggi G, Casadio C, Pischedda F, et al. Combined radiosurgical treatment of Pancoast tumor. Ann Thorac Surg 1994;57:198-202.

23. Chadeyras JB, Mazel C, Grunenwald D. Vertebral en bloc resection for lung cancer: twelve years' experience. Ann Chir 2006;131:616-22.

24. Sanli A, Onen A, Yücesoy K, et al. Surgical treatment in non-small cell lung cancer invading to the chest wall (T3) and vertebra (T4). Tuberk Toraks 2007;55:383-9.

25. Yokomise H, Gotoh M, Okamoto T, et al. En bloc partial vertebrectomy for lung cancer invading the spine after induction chemoradiotherapy. Eur J Cardiothorac Surg 2007;31:788-90.

26. Anraku M, Waddell TK, de Perrot $M$, et al. Induction chemoradiotherapy facilitates radical resection of T4 non-small cell lung cancer invading the spine. J Thorac Cardiovasc Surg 2009;137:441-7.e1.

27. Schirren J, Dönges T, Melzer M, et al. En bloc resection of non-small-cell lung cancer invading the spine. Eur J Cardiothorac Surg 2011;40:647-54.

28. Deslauriers J, Tronc F, Fortin D. Management of tumors involving the chest wall including pancoast tumors and tumors invading the spine. Thorac Surg Clin 2013;23:313-25.

29. Yokoi K, Taniguchi T, Usami N, et al. Surgical management of locally advanced lung cancer. Gen Thorac Cardiovasc Surg 2014;62:522-30.

30. Sakanoue I, Hamakawa H, Onishi E, et al. Giant cell tumor of the rib with direct invasion into the thoracic spine. Gen Thorac Cardiovasc Surg 2017;65:293-6.

31. Koizumi K, Haraguchi S, Hirata T, et al. Surgical treatment of ,lung cancer with vertebral invasion. Ann Thorac Cardiovasc Surg 2004;10:229-34.

32. Fadel E, Missenard G, Court C, et al. Long-term outcomes of en bloc resection of non-small cell lung cancer invading the thoracic inlet and spine. Ann Thorac 
Surg 2011;92:1024-30.

33. Mody GN, Bravo Iñiguez C, Armstrong K, et al. Early Surgical Outcomes of En Bloc Resection Requiring Vertebrectomy for Malignancy Invading the Thoracic Spine. Ann Thorac Surg 2016;101:231-6.

34. Dartevelle PG, Mitilian D, Fadel E. Extended surgery for T4 lung cancer: a 30 years' experience. Gen Thorac Cardiovasc Surg 2017;65:321-8.

35. Collaud S, Waddell TK, Yasufuku K, et al. Long-term outcome after en bloc resection of non-small-cell lung cancer invading the pulmonary sulcus and spine. J Thorac Oncol 2013;8:1538-44.

36. Collaud S, Fadel E, Schirren J, et al. En Bloc Resection of Pulmonary Sulcus Non-small Cell Lung Cancer Invading the Spine: A Systematic Literature Review and Pooled Data Analysis. Ann Surg 2015;262:184.

37. Zhang XM, Fournel L, Lupo A, et al. En-bloc resection of thoracic tumors invading the spine: a single-center experience. Ann Thorac Surg 2019;108:227-34.

38. Rusch VW, Giroux DJ, Kraut MJ, et al. Induction chemoradiation and surgical resection for superior sulcus non-small-cell lung carcinomas: long-term results of Southwest Oncology Group Trial 9416 (Intergroup Trial 0160). J Clin Oncol 2007;25:313-8

39. Martin J, Ginsberg RJ, Venkatraman ES, et al. Long-term results of combined-modality therapy in resectable nonsmall-cell lung cancer. J Clin Oncol 2002;20:1989-95.

Cite this article as: Loi M, Mazzella A, Desideri I, Fournel L, Hamelin EC, Icard P, Bobbio A, Alifano M. Chest wall resection and reconstruction for lung cancer: surgical techniques and example of integrated multimodality approach. J Thorac Dis 2020;12(1):22-30. doi: 10.21037/jtd.2019.07.81
40. Thomas M, Rübe C, Hoffknecht P, et al. Effect of preoperative chemoradiation in addition to preoperative chemotherapy: a randomised trial in stage III non-smallcell lung cancer. Lancet Oncol 2008;9:636-48.

41. Pless M, Stupp R, Ris HB, et al. Induction chemoradiation in stage IIIA/N2 non-small-cell lung cancer: a phase 3 randomised trial. Lancet 2015;386:1049-56.

42. Chen D, Wang H, Song X, et al. Preoperative radiation may improve the outcomes of resectable IIIA/N2 nonsmall-cell lung cancer patients: A propensity score matching-based analysis from surveillance, epidemiology, and end results database. Cancer Med 2018;7:4354-60.

43. Trastek VF, Pairolero PC, Piehler JM, et al. En bloc (non-chest wall) resection for bronchogenic carcinoma with parietal fixation. Factors affecting survival. J Thorac Cardiovasc Surg 1984;87:352-8.

44. Zhao Y, Wang W, Liang H, et al. The Optimal Treatment for Stage IIIA-N2 Non-Small Cell Lung Cancer: A Network Meta-Analysis. Ann Thorac Surg 2019;107:1866-75.

45. Weyant MJ, Bains MS, Venkatraman E, et al. Results of chest wall resection and reconstruction with and without rigid prosthesis. Ann Thorac Surg 2006;81:279-85.

46. Hayashi T, Sakakura N, Ishimura D, et al. Surgical complication and postoperative pulmonary function in patients undergoing tumor surgery with thoracic wall resection. Oncol Lett 2019;17:3446-56. 